\title{
scripted
}

Volume 14, Issue 1, June 2017

\section{Book review: Ethical Judgments: Re-Writing Medical Law}

Stephen W Smith, John Coggon, Clark Hobson, Richard Huxtable, Sheelagh McGuinness, José Miola, and Mary Neal (Editors)

Oxford: Hart Publishing, 2017. 290 pages.

ISBN: 9781849465793. £40.

Reviewed by Catriona McMillan*

(c) (1) $\circledast \Theta$

(C) 2017 Catriona McMillan

Licensed under a Creative Commons Attribution-NonCommercial-

NoDerivatives 4.0 International (CC BY-NC-ND 4.0) license

DOI: $10.2966 /$ scrip.140117.123

* PhD Candidate, School of Law, University of Edinburgh 
Ethical Judgements: Re-Writing Medical Law is an engaging and timely addition to the socio-legal literature on the interaction between medical law, ethics, and the judiciary. It addresses and makes explicit, in a rather original manner, ${ }^{1}$ the complex ethical questions that "hard" medical law cases pose for the judiciary. From cases concerning the beginning of life, the end of life, and professional obligations, judges have long grappled with the complex interaction between legal and moral dilemmas in medicine. This volume presents a collection of nine key medical law cases in the UK, each case "re-written" from the perspectives of a group over 30 academics from varying backgrounds.

Each case is approached via a two-stage process. First, the decisions are "re-written" in the form of two judgements (both based on the established facts of the case, and the law at the time) and then engaged with by two authors: one from a legal perspective, and another from an ethical perspective. Each case section thus consists of four parts: two judgements and two commentaries. All of these analyses are based upon a simple premise: what if, in addition to decisionmaking from a legal perspective, judges were required to acknowledge and reason their ethical positions, and how might that impact upon the final decision? Thus, in the editors' own words:

This collection, then, involves an ethical re-writing of health care law. What has resulted is somewhat akin to a work in counterfactual history; a sort of 'alternate world' opened up by asking 'what if...?' (p. 4)

1 The text acknowledges the Feminist Judgments Project (a research project in which feminist socio-legal scholars wrote alternative judgments to significant cases from a feminist perspective) but also notes that they did not entirely follow its lead. See Rosemary Hunter, Clare McGlynn, and Erika Rackley (eds.), Feminist Judgments: From Theory to Practice (Oxford: Hart Publishing, 2010). 
The book's introduction also calls for the examination of three overarching questions. First, in making medico-legal decisions in court, have judges drawn conclusions based on the requirements of law, or have they instead drawn upon extra-legal factors, meaning that there were other possible outcomes to the case? Second, should judges embrace extra-legal factors in their decision-making where the "right" legal answer is unacceptable or unclear? Third, should further engagement between medical law and ethics occur, or should they be formally detached? The answers to each these are drawn out in the varying perspectives of the lawyers, ethicists and social scientists who author their contributions to the re-writing of, and commentary on, these landmark cases.

The book opens with the case of Re A (Conjoined Twins: Surgical Separation) [2001] Fam 147, where the court had to consider whether it was lawful to separate conjoined twins even though it was certain that the procedure would result in one of them dying. Suzanne Ost (Lancaster University) and Richard Huxtable (University of Bristol), as the judicial "re-writers", sat as the Court of Appeal. Dismissing and upholding the appeal respectively, each author advances their judicial analysis through quite different legal lenses. While both agree that actus reus for murder was present if the procedure were to take place, they differ in judgement on the matter of whether mens rea was present. These decisions are followed by a legal commentary from Kirsty Moreton (Keele University), who notes, among other things, that both judgements combine innovative and traditional interpretations of the law. Moreton's analysis is followed by a commentary from Jackie Leach Scully (Newcastle University), who provides ethical reflection on some of the key concepts on these judgements.

The second section looks at $R$ (on the application of Axon) $v$ Secretary of State for Health [2006] EHWC 37 (Admin), where the court considered the circumstances in which a patient under 16 years of age could consent to an 
abortion without their parents' knowledge or consent. Here, Jonathan Herring (Oxford University) and Hazel Biggs (University of Southampton) strongly support the ethical principle of autonomy in their judgements. Elizabeth Wicks (Leicester University), in providing legal analysis, comments that while defence of autonomy is to be praised, there is much work still to be done to resolve inconsistencies within the law on this principle. The ethical commentary by David Archard (Queen's University Belfast) explores the relation between autonomy and confidentiality between doctor and minor.

The third judgement addressed by scholars is Airedale NHS Trust $v$ Bland [1993] AC 789. Here the court was asked to consider whether artificial nutrition and hydration $(\mathrm{ANH})$ could lawfully be withdrawn from a patient in a persistent vegetative state. Writing as Law Lords, Stephen Smith (Cardiff University) and David Jones (Anscombe Bioethics Centre) deliver very different judgements on this issue, highlighting the tension between quality of life and sanctity of life arguments. Hazel Biggs discusses these judgements and the withdrawal of ANH from a legal perspective, followed by James Childress (University of Virginia), who reasons that the withdrawal of ANH can be ethically acceptable in certain circumstances.

The fourth case re-writes $R v$ Human Fertilisation and Embryology Authority, ex parte Blood [1999] Fam 151, which concerned the question of whether a woman could posthumously use her husband's sperm to conceive a child. Graeme Laurie (University of Edinburgh) and Emily Jackson (LSE) both posit written consent (and its absence in this case) as decisive in considering whether the posthumous removal of sperm is lawful. These judgements are followed by a legal commentary from Mary Neal (University of Strathclyde), who explores some of the wider themes of the case, such as human dignity, and their implications. Heather Widdows (University of Birmingham) then analyses the case from an 
ethical perspective, emphasising the duty of ethicists to question the justification and wider implications of legal principles, such as those in Blood.

The fifth case addresses Bolitho v Hackney Health Authority [1998] AC 232, which concerned the question of how courts should treat medical expertise when considering medical negligence, and the extent to which they should be involved in clinical decision-making. Writing as Law Lords, José Miola (Leicester University) and Jonathan Montgomery (UCL) agree on many aspects of the case, for example that a level of judicial restraint is appropriate in cases concerning treatment and diagnosis, but they differ in their structural perspective on law with regard to the place of ethics within it. The legal commentary for this section, provided by Nicky Priaulx, Martin Weinel and Chris Goldsworthy (all Cardiff University), supports Miola's judgement, noting that context is a critical element when making determinations in this field. In the final section on this case, John Harrington (Cardiff University) posits that Montgomery and Miola's judgements must be contextualised alongside the decline in plausibility of the Bolam ${ }^{2}$ test, and links this to a "crisis of legal form" associated with the welfare state.

The sixth case addresses $R v$ Bourne [1939] 1 KB 687, a landmark case concerning whether a doctor had lawfully performed an abortion on a 14-year old girl. Sheelagh McGuinness (University of Bristol) writes her judgement through the lens of women's rights and justice; in contrast, Joseph Dellapenna (Villanova University) provides a judgement which focuses upon the rights of the "unborn child". Lois Bibbings' (University of Bristol) legal commentary provides background and summaries of the case as it was originally decided, and "re-written", while Françoise Baylis's (Dalhousie University) ethical commentary explores whether Bourne may be said to have acted for the right reasons.

2 Bolam v Friern Hospital Management Committee [1957] 1 WLR 582. 
The seventh case, Chester $v$ Afshar [2005] 1 AC 134, looked at how the law should respond to a surgeon's failure to properly explain the inherent risks of an operation to their patient. Here, Rob Heywood (UEA) and Sarah Devaney (University of Manchester) advance judgements which recognise the interplay between legal rules and ethical principles. Acknowledging that attempting to marry these principles resulted in the "bending" of law to suit the Claimant, José Miola then provides an alternative reading of the law in his commentary. This is followed by John Coggon (University of Bristol), who reflects on the concept of autonomy and its protection in medical law.

The eighth case addressed by scholars, $R$ (on the Application of Nicklinson and Another) v Ministry of Justice [2014] UKSC 38, considered a legal challenge to the law prohibiting assisted suicide. Writing as Supreme Court Justices, John Coggon and Richard Huxtable offer different theoretical viewpoints on the relationship between particular theories of philosophy, ethics and law in this context. Clark Hobson (University of Birmingham) then explores their approaches from a legal perspective, followed by Stephen W Smith's ethical commentary, which highlights some of the key ethical differences between the two judgements.

The ninth and final case discussed is St George's Healthcare NHS Trust v S [1999] Fam 26. Here, the court was asked to consider whether a woman had a right to refuse a caesarean section, even if that meant she and her foetus might die. Sarah Fovargue (Lancaster University) and Mary Neal, sitting as the Court of Appeal, advance rather different perspectives on the extent to which the law should value and protect foetal life. Sheelagh McGuinness then reflects on the original judgement of the case, framing her analysis with the concept of 
"gendered harms"3 in pregnancy and reproduction. Sorcha Uí Chonnachtaigh (Keele University) provides a feminist ethical critique of the re-written judgements.

Having revealed a range of possible structural perspectives on the law, the book concludes by considering some of the lessons learned from these exercises in judicial reasoning. The authors make clear that not only do these alternative judgements highlight how the law might have been different, but also how ethical concerns might have impacted on judicial reasoning in these cases. Noting that this project was not without constraints, it goes on to consider some of these, including the influence of academia upon the minds of judges. The authors conclude, however, by addressing one of the biggest challenges these kinds of cases pose to medical law, as highlighted by this volume: what is the value of ethical, rather than legal consistency, in cases where there is no obvious right or wrong outcome? Their answer is that the book demonstrates that a "court of morals" would not necessarily achieve decisions or outcomes any more palatable than those that have been arrived at by our courts of law.

Overall, Ethical Judgements: Re-Writing Medical Law is a fascinating volume that delivers, as the authors conclude:

...new insights and perspectives not only into what different arguments tell us the law does and should say, but also into how we - non judges - might approach controversial medico-legal questions when challenged to do so as (admittedly imagined) judges. (p. 256)

3 McGuinness borrows this concept from Robin West, Caring for Justice (New York: NYUP, 1997). 
The alternative judgements given in the book, often from quite different perspectives, coupled with the legal and ethical commentaries, provide a compelling demonstration of the "alternative histories" that might have been created within the field of medical law. Not only must we be alive to the legacy these decisions provide and their real-world repercussions, but also to how they might have been different, and thus continue to question the place of ethics in the courts. It is therefore important to be aware of, and challenge, alternative possibilities in this field by asking: "what if?". 